$1-2009$

\title{
Towards an Agenda for SoTL in Africa?
}

Ian Scott

University of Cape Town, ian.scott@uct.ac.za

Follow this and additional works at: https://digitalcommons.georgiasouthern.edu/ij-sotl

\section{Recommended Citation}

Scott, lan (2009) "Towards an Agenda for SoTL in Africa?," International Journal for the Scholarship of Teaching and Learning: Vol. 3: No. 1, Article 3.

Available at: https://doi.org/10.20429/ijsotl.2009.030103 


\title{
Towards an Agenda for SoTL in Africa?
}

\begin{abstract}
Sub-Saharan Africa, a diverse, largely impoverished and troubled region, has a pressing need for economic and social development. Given the ever-increasing importance of advanced knowledge and skills in the contemporary world, the education systems in many African countries are a major concern. In particular, it is essential that the capacity of the region's higher education systems to produce capable graduates should grow rapidly and strongly, in the interests of internal development and to avoid further widening of the North-South divide. This essay gives a brief account of the situation and some key issues in sub-Saharan African higher education, outlines aspects of South Africa's experience that may prefigure developments elsewhere on the continent, and offers a view of what kind of role SoTL might play in developing-country contexts.
\end{abstract}

\section{Keywords}

Africa, Higher education, Development, Widening participation, Graduate output SoTL

Creative Commons License

\section{(c) $(i) \Theta \Theta$}

This work is licensed under a Creative Commons Attribution-Noncommercial-No Derivative Works 4.0 License. 


\title{
Towards an Agenda for SoTL in Africa?
}

\author{
I an Scott University of \\ Cape Town Cape Town, \\ South Africa \\ ian.scott@uct.ac.za
}

\begin{abstract}
Sub-Saharan Africa, a diverse, largely impoverished and troubled region, has a pressing need for economic and social development. Given the ever-increasing importance of advanced knowledge and skills in the contemporary world, the education systems in many African countries are a major concern. In particular, it is essential that the capacity of the region's higher education systems to produce capable graduates should grow rapidly and strongly, in the interests of internal development and to avoid further widening of the North-South divide. This essay gives a brief account of the situation and some key issues in sub-Saharan African higher education, outlines aspects of South Africa's experience that may prefigure developments elsewhere on the continent, and offers a view of what kind of role SoTL might play in developing-country contexts.
\end{abstract}

Key words: Africa, higher education, development, widening participation, graduate output, SoTL

\section{I ntroduction}

To most parts of the world, Africa is still the remote continent. On the infrequent occasions when African countries, particularly those in sub-Saharan Africa, feature in international news, it is unfortunately almost always for negative reasons like war, disease and famine. Although the diversity of African countries is probably as great as that on any other continent - from the anarchic failed state of Somalia, to oil-rich but still largely impoverished Nigeria, to stable and steadfastly democratic Botswana - it is probably fair to say that Africa is generally not taken seriously by the rest of the world except as being the continent most in need of aid.

Much the same can be said of higher education in sub-Saharan Africa. Only a handful of universities have a name outside the continent. This is not surprising in that many African institutions have suffered greatly from resource-starvation, political control, the brain drain, and the North-South divide, not least in internet access. Little recognised research is produced: “... in terms of global population size, developing countries contribute very little to world development. The situation is worse in Africa as Brazil, China and India claim the largest portions of the developing countries' research outputs" (DST, 2006). In relation to the educational mission of universities, there is little African presence in higher education journals, books or international SoTL conferences.

However, growth and renewal are taking place in a number of sub-Saharan African countries (see for example Fleshman, 2003), in democracy, in the economy and to an extent in higher education, where enrolment is growing at $15 \%$ a year, the highest rate in the world (Africa Higher Education, 2008) albeit from a very low base. This paper offers a brief account of the situation and some key issues in sub-Saharan African higher education, and a view of how SoTL might contribute to development in this large and still troubled region. 


\section{The State of Higher Education in Sub-Saharan Africa}

\section{Sub-Saharan Africa Overall}

Among the major contextual differences between first- and third-world countries is that in the latter, in most cases, only a very thin layer of the population have access to good educational opportunities. This layer inevitably coincides largely with privilege and relative wealth. The shape of the education system in many African countries is a broad, stepped pyramid. In sub-Saharan Africa, universal primary education has not been achieved, with only $60 \%-70 \%$ of the age group completing primary school. Secondary school places are in short supply and attrition continues steadily, with the result that only about $30 \%$ of the age group complete junior secondary. "In the end only one in four or five African youth complete secondary education" (Bregman, 2008: 8-9).

Higher education represents another abrupt narrowing of the pyramid. The measure of participation used in this paper is the Gross Enrolment Rate (GER), a UNESCO measure in which total enrolment (of any age) in a grade or phase is expressed as a percentage of the relevant age group in the population. For higher education the denominator is the 20-24 year-old age group. On this measure, sub-Saharan Africa has an average higher education GER of only $5 \%$. By contrast, the average for North America and Western Europe is $70 \%$ (UNESCO, 2008). The following table shows some of the disparities:

Table 1: HE GER of selected countries in 2005; Total enrolment as percentage of 20-24 age-group

\begin{tabular}{|l|l|}
\hline Sub-Saharan Africa (av) & $5 \%$ \\
\hline Nigeria & $10 \%$ \\
\hline South Africa & $15 \%$ \\
\hline United Kingdom & $60 \%$ \\
\hline Australia & $72 \%$ \\
\hline United States & $83 \%$ \\
\hline South Korea & $91 \%$ \\
\hline
\end{tabular}

Source: UNESCO 2007

The low participation rates in sub-Saharan African countries are echoed in the size of their higher education systems. Nigeria has the biggest population and higher education system, with a total enrolment of some 1.3 million in 2004. South Africa is next with nearly 750,000 students. The third largest system, Ethiopia's, has under 200,000 students. These three countries have more than half of all tertiary students in subSaharan Africa, so the systems in the rest of the countries are very small.

Acute shortages of state resources have led a number of African countries to look to private higher education as the only viable means of substantial expansion. For-profit and not-for-profit private institutions, run mainly by entrepreneurs and religious organisations, have proliferated in some countries (Varghese, 2008), leading to a range of policy, regulatory and quality assurance dilemmas for governments.

Meaningful aggregated data on graduate output in sub-Saharan Africa are not available, and there is evidently much variation between countries. At least partly because most 
of the student intake represents a highly-selected and relatively affluent elite, drop-out rates are estimated to be relatively low in a number of countries, estimated very roughly at below 50\% (Africa Higher Education, 2008). Given the low level of participation, however, the percentage of the age-group that graduates is very small, probably about 3\%. These figures have major implications for development, as discussed below.

\section{South Africa}

South Africa contrasts with other African countries in a number of key respects, reflecting its different colonial history. It is in various ways a special case but merits a particular focus as its experience may prefigure developments in higher education elsewhere on the continent.

South Africa has the highest overall participation rate among the larger African countries (15\% in 2005) but does not compare favourably with other emerging economies in this respect, the benchmark being $20 \%$. Probably more important, however, are its continuing racial disparities, as shown in the following table:

Table 2: HE GER in South Africa in 2005, by 'race':

Total enrolment in 2005 as percentage of 20-24 age-group

\begin{tabular}{|c|c|}
\hline White & $60 \%$ \\
\hline Indian & $51 \%$ \\
\hline Coloured & $12 \%$ \\
\hline Black/African & $12 \%$ \\
\hline
\end{tabular}

Source: Scott, Yeld and Hendry 2007

As discussed below, these racially skewed participation rates form a key element of the backdrop to interpreting higher education performance patterns in South Africa, about which there is considerable information that has implications for SoTL.

The overall performance of the sector is very poor. Recent analyses of first-time entering student cohorts (Scott, Yeld and Hendry, 2007; Letseka and Maile, 2008) have revealed the following patterns:

- Overall, only $30 \%$ of the intake graduate within five years. Since most of South Africa's undergraduate degrees and diplomas are nominally three-year programmes, this represents very low efficiency. It is in fact estimated that under $45 \%$ of the intake will ever graduate.

- Even in the best-performing sub-sector of provision, i.e. the "contact" universities (excluding distance education), only $50 \%$ of the intake graduate within five years. Drop-out in vocational diplomas, where there is particularly strong need for good graduates, is much higher, around $60 \%$.

- While rapid progress has been made with black student access (about $70 \%$ of total higher education enrolment is now black), these gains are being neutralised by racially skewed success rates. In most contact university programmes, black graduation rates are under half of those for whites, and (despite the enrolment and population demographics - under $10 \%$ of the population is white) there are fewer black than white graduates.

- The net effect is that under 5\% of the 20-24 year-old black age-group are succeeding in any form of higher education. 
It is true that many higher education systems have high drop-out rates. However, in South Africa (and other developing countries) high attrition occurs in an environment of low and racially skewed participation. This is unacceptably wasteful of the country's talent, especially that in the black majority: if "educability" is randomly distributed across populations, most of the student intake, being in the top decile in terms of prior educational attainment, must have the academic potential to succeed, yet are not being successfully accommodated by the system.

This situation has major negative implications for South Africa's development and stability as an emerging democracy and economy. In relation to economic development, which is crucial for alleviating poverty and avoiding widening of the North-South divide, shortage of technical and high-level skills has been identified as the main obstacle. Moreover, lack of "equity of outcomes" is prejudicing black social and economic advancement, which, in addition to the issue of social justice, is likely to pose an increasing threat to stability. In fact, it is evident from the performance patterns that growth in high-level skills must come predominantly from the black majority, so the equity agenda - which has in practice been largely marginalised in higher education has become critical for all forms of development.

Attrition in higher education is of course attributable to a range of factors. In South Africa, poverty and poor quality (with persisting inequalities) in K-12 schooling - the legacy of apartheid - still have a pervasive influence, and many faculty do not see it as their responsibility to address resulting student underpreparedness for tertiary study. Regrettably, however, there is scant likelihood of significant improvement in these external factors in the foreseeable future. Poverty will not readily be alleviated, and, as various analyses have shown, the school sector faces so many post-apartheid challenges that substantially raising the number of well-prepared school-leavers is likely to be beyond its reach for a generation (see for example Bloch, 2008; Newman, 2008; Scott, Yeld and Hendry, 2007:31-37). The choice for higher education, therefore, is to accept the status quo as unavoidable, or to be willing to adjust its own practices - from curriculum design to delivery in the classroom - to meet the needs of a growing, changing and increasingly diverse student body without compromising standards, and thus to make its proper contribution to development.

The relationship between the South African experience and challenges for the rest of Africa is discussed below.

\section{Some Key Challenges for African Higher Education}

As outlined earlier, all sub-Saharan African countries need to substantially increase participation in higher education, in the interests of their own internal development and their efforts to achieve a competitive international niche. The need is all the more pressing because of the loss of skills and talent from the brain drain and from HIV-AIDS. South Africa has done more than its African peers (except for the small island nation of Mauritius) to raise its participation rate, and while it has its own unique conditions, its experience is of interest.

Perhaps the central lesson of the South African experience is that focusing only on access can have quite unintended and counter-productive consequences. Broadening the intake without critically reviewing core educational structures, assumptions and practices has in South Africa's case led to damaging inequity in outcomes, demoralisation for many thousands of talented individuals, and unacceptable wastage of human and material resources. Moreover, it is historically marginalised social classes and ethnic 
groups that are inevitably most negatively affected. What is needed is not just widening participation but widening successful participation, i.e. access accompanied by equity of outcomes, if the central educational challenge of the region - to substantially improve graduate output in terms of numbers, quality and mix - is to be met.

Is the South African experience relevant to the rest of sub-Saharan Africa? It is true that, despite its stronger resources, South Africa's school system compares poorly with those of a number of other African countries (see for example Reddy, 2003; Yeld, 2003). It is also the case, however, that in almost all sub-Saharan African countries, only a small social elite have access to good quality secondary schooling and thence to higher education. This is not sustainable, either politically, as more democratic dispensations evolve, or economically, in a globalising world. As the process of expansion of access continues - in public and/or private provision - the intake will grow larger than the elite layer, increasing the proportion of students who are not well prepared for the traditional, inherited forms of higher education that prevail. In these circumstances, it is quite possible that the issues and tensions experienced in South Africa will come to the fore.

Another dimension of the importance of successfully expanding higher education in Africa is the need to produce more school teachers. Apart from material resource shortages, there are not enough qualified teachers to improve the capacity and quality of the school system, which severely constrains the supply of capable candidates for higher education. It has been estimated, for example, that some 3 million new teachers will be needed by 2015 if sub-Saharan Africa is to be able to provide nine to ten years of basic education for all its children (Hoppers and Obeegado, 2008:23). Given that total sub-Saharan African tertiary enrolment is at present only about 3.5 million (UNESCO, 2008), it is clear that participation is far from being sufficient to meet such key developmental needs.

It is essential to break this vicious cycle. Material resources may be found through foreign aid, but the great majority of the educated and skilled people needed to take a country forward must be grown at home. While higher education has a range of roles in developing societies (not least the creation and application of new knowledge), producing good graduates is its central and unique responsibility. SoTL can play a special part in bringing this about.

\section{The Significance of SoTL for African Development}

Considering the importance of development to Africa, and the key role of higher education in facilitating individual and societal advancement, there are high stakes involved in creating structures and approaches that can responsibly expand higher education and successfully grow graduate output across the continent.

It is evident that existing structures and approaches are not adequate or well-geared to meeting this challenge. There are of course major material and external constraints, but, it is argued, this does not absolve higher education itself of its social obligation particularly acute in developing countries - to be willing to consider the effectiveness of its traditional practices for meeting contemporary needs in the local and regional context, without devaluing the principles of scholarship. In many countries, coloniallyinherited entry criteria and curricula are blocking the aspirations of talented-butdisadvantaged individuals, and the South African experience highlights the risks of mismatch between educational processes and learning needs.

If fresh approaches are called for, what should they be based on? An academic community should surely place its faith in systematic enquiry and scholarship to address 
such challenges. It is therefore fair to ask what role SoTL could play in changing who benefits from higher education. The following are some broad suggestions:

- First, it is critical to work towards an in-depth and well-theorised understanding of how widening successful participation can be accomplished in developing countries, particularly in the sub-Saharan African context, through both public and private provision. Such work can never be completed, of course, but the existence of misguided policy in many countries suggests that it is critical for governments and institutions, as well as the academic communities involved, to be influenced to recognise the educational implications of expansion and the importance of ensuring that effective educational strategies - the necessary conditions for succeeding - are identified and implemented. This kind of educational research may not be seen as a traditional SoTL area; however, unless research-for-policy has roots in knowledge of teaching and learning, it risks having serious unintended consequences, as shown in South Africa and various other contexts.

- Secondly, it is clear in South Africa, and may apply in other African countries, that the inherited curriculum frameworks that higher education has continued to use do not meet the needs of the majority of the intake that the sector needs to accommodate. It is essential that educational expertise, based on systematic knowledge of teaching and learning in Kreber's (2002) broad sense, should underpin curriculum development in contexts where assumptions must differ significantly from those of the developed Western world.

- Thirdly and perhaps most importantly, extending the benefits of higher education in Africa requires willing engagement and creativity from the faculty themselves, in designing and teaching in fresh ways that suit the realities of students who are talented but not conventionally well-prepared. Widening successful participation is therefore very much a matter of hearts and minds. It calls for, inter alia, psychological ownership of responsibility for a wider intake, based on well-founded belief that many more people can succeed in higher education. To achieve this, it is necessary to confront the common view that "non-traditional" students, even those in the top decile of prior attainment, are "unteachable" and should not have a place in higher education.

Given the nature of the academic community, appealing to academics' intellectual integrity though rigorous educational research, offering researchinformed educational approaches and strategies that can be effective in accommodating a diverse student body, and providing faculty with a conceptual framework for engaging in educational scholarship themselves, will probably be essential conditions for achieving positive change in the outcomes of higher education in Africa. The limitations of bureaucratic coercion and narrow compliance are now well-known.

If this argument holds, the role of SoTL is critical to the development of higher education in sub-Saharan Africa. The continent needs regional and national structures and networks that facilitate professional development in teaching-and-learning, and promote a visible role for educational expertise and for SoTL as a manifestation of this. Lee Shulman's celebrated expression of the significance of SoTL "going public" may be particularly relevant in the African context, as a key means of influencing public policy as well as the attitudes and practices of the academic community.

Putting SoTL on the African map will not be simple and probably not rapidly achieved. It is hoped, however, that the international educational research and SoTL communities will consider responding to the need in appropriate ways. A start might be made by, for 
example, seeking to identify individuals in African higher education who might be drawn into SoTL networks (as the leadership of this journal has done), and including a special developing-country theme or strand in international SoTL conferences.

It is possible that, if democracy and economic change continue to spread on the continent, African governments, higher education organisations and supporting agencies will become increasingly open to considering well-researched and socially sensitive ideas for building the educational capacity of universities to meet contemporary needs in their contexts. A key question for those of us in Africa is to what extent SoTL can be mobilised to address this challenge.

\section{References}

Africa Higher Education (2008). Higher Education in Sub-Saharan Africa.

http://www. arp. harvard.edu/AfricaHigherEducation/Data.html (accessed 2008-12-07) http: // www.arp. harvard.edu/AfricaHigherEducation/Factoids. html (accessed 2008-12-07)

Bloch, G. (2008, July 31). Fixing schools: a 30-year task. Pretoria: Pretoria News, p.12.

Bregman, J. (2008). Towards 9-10 years of Education For All: Promising Practices and Strategies. ADEA Biennale 2008. Paris: Association for the Development of Education in Africa (ADEA).

http: // www. adeanet. org/adeaPortal/adea/Biennale 2008/Documentation/Papers presentation/03. Session 3/Final PDF documents/Session 32D" Theme 1 Synthesis Report ENG.pdf (accessed 2008-11-23)

DST (Department of Science and Technology, South Africa) (2006). Keynote address by Minister Mosibudi Mangena, 3rd African Regional Conference on Engineering Education. Pretoria: Department of Science and Technology.

http: //www.dst. gov.za/mediaroom/speeches/speech.2007-05-22.7692818514 (accessed 2008-11-23)

Fleshman, M. (2003). Africa struggles to attain development goals. Africa Recovery, Vol.17 \#3 p10. New York: United Nations.

http://un.org/ecosocdev/geninfo/afrec/vol17no3/173mdg.htm (accessed 2008-12-07)

Hoppers, W. and Obeegadoo, S. (2008). General Synthesis Report, ADEA Biennale 2008. Paris: Association for the Development of Education in Africa (ADEA).

http: // www. adeanet. org/adeaPortal/adea/Biennale\% 202008/Documentation/Papers\% 20 for\% 20presentation/ 03. \% 20Session\% 203/Final\% 20PDF\% 20documents/Session\% 203\% 20Doc\% 201\% 20General\% 20Synthesis\% 20Report\% 20ENG. pdf

(accessed 2008-11-23)

Kreber, C. (2002). Teaching Excellence, Teaching Expertise, and the Scholarship of Teaching. Innovative Higher Education, 27(1), 5-23.

Letseka, M. and Maile, S. (2008). High university drop-out rates: a threat to South Africa's future. Pretoria: Human Sciences Research Council.

Newman, L. (2008, October 23). 'SA education standard is dismal'. Durban: The Mercury, p. 6. 
Reddy, V. (2003). TIMSS 2003 results. Pretoria: Human Sciences Research Council. http://www.hsrc.ac.za/research/programmes/ESSD/timss2003/index. html (accessed 2008-12-13)

Scott, I., Yeld, N. and Hendry, J. (2007). A case for improving teaching and learning in South African higher education. Higher Education Monitor No. 6. Pretoria: Council on Higher Education. http://www.che.ac.za/documents/d000155/index. php (accessed 2008-12-06)

UNESCO (2007). Education For All Report 2008. Paris: UNESCO.

Varghese, N. (2008). State, markets, faith and proliferation of private higher education in Africa. Paris: UNESCO

Yeld, N. (2003). Academic literacy and numeracy profiles: An analysis of some results from the AARP and TELP tests of incoming students (2001/2002 entry years). In SAUVCA-CTP Higher Education Admissions Project: Into Higher Education - Perspectives on Entry Thresholds and Enrolment Systems. ISBN 0-620-31204-1, 21-52. 